\title{
Does oral health-related quality of life of patients after solid organ transplantation indicate a response shift? Results of a systematic review
}

\author{
Gerhard Schmalz ${ }^{1 *}$, Jens Garbade ${ }^{2}$, Otto Kollmar ${ }^{3}$ and Dirk Ziebolz
}

\begin{abstract}
Background: The physical oral health and dental behaviour of patients after solid organ transplantation (SOT) has repeatedly been reported as insufficient. The objective of this systematic review was to detect whether the oral health-related quality of life (OHRQOL) of patients after SOT is reduced compared to that of healthy individuals.
\end{abstract}

Methods: A systematic literature search was performed by two independent individuals based on the PubMed, Web of Science and Scopus databases by using the following search terms: "transplantation" AND "oral health-related quality of life". The findings were checked to determine eligibility, whereby publication prior to 31 October 2020, examination of adult patients (age at least 18 years) with SOT, reporting of an OHRQoL outcome and full text in English language were the prerequisites for inclusion in the qualitative analysis. Quality appraisal of the included studies was performed using the Agency for Healthcare Research and Quality methodology checklist.

Results: Seven of 25 studies that examined patients after kidney (3), heart (2), liver (1) and lung transplantation (1) were included. Four studies included healthy controls, and five studies included a cohort of patients before transplantation for comparison. Clinical oral health examinations were heterogeneous between groups. The majority of studies (5/7) applied the short form of the "Oral Health Impact Profile" (OHIP 14) to assess OHRQoL. The OHIP 14 values ranged between 1.7 and 8.9 across studies, indicating an unaffected or just slightly reduced OHRQoL. Only one study found better OHRQoL in patients after SOT compared to a group before SOT, and one study confirmed worse OHRQoL of SOT recipients compared to a healthy control. Only two studies revealed an association between OHRQOL and oral health parameters. Furthermore, two studies each found a relationship between OHRQOL and general health-related quality of life or disease-related parameters.

Conclusions: Patients after SOT show an unaffected or only slightly reduced OHRQOL, which was mainly independent of the insufficient oral status. This might indicate a shift in the perception threshold for oral diseases and conditions caused by the general health burden related to the SOT.

Keywords: Oral health, Oral health-related quality of life, Solid organ transplantation

*Correspondence: Gerhard.schmalz@medizin.uni-leipzig.de

1 Department of Cariology, Endodontology and Periodontology,

University of Leipzig, Liebigstr. 12, 04103 Leipzig, Germany

Full list of author information is available at the end of the article

\section{Background}

For many different end-stage organ diseases or conditions, solid organ transplantation (SOT) is an established and promising therapeutic approach that improves the physical and mental health of patients [1]. Due to successful surgical and posttransplant care, patient survival 
and morbidity have improved in recent decades, making quality of life issues increasingly relevant [2]. The quality of life of patients with SOT, including kidney (KTx), liver (LTx), lung (LuTx) and heart (HTx), is complex, and different physical, psychological, (psycho-)social and environmental parameters are of relevance [2]. Organ transplantation is a life-changing experience for patients and their relatives, making cognitive and emotional integration of the received organ a mandatory condition [3]. In general, health-related quality of life (HRQoL) is improved after SOT; however, anxiety, depression and psychosocial impairment are frequently occurring problems, making psychosocial support interventions recommended $[2,4,5]$.

In addition to general disease-related parameters, HRQoL can be influenced by oral conditions [6]. In particular, tooth loss has the potential to affect the HRQoL of patients [6]. The specific subaspect of HRQoL in this context is oral health-related quality of life (OHRQoL), a multidimensional model including different physical and psychosocial issues [7]. This OHRQoL assesses the individual perception of a patient's oral conditions and their perceived influence on oral function, psychosocial impacts, pain and orofacial appearance $[7,8]$. Regularly, oral diseases, such as periodontitis, tooth loss (especially occluding pairs of teeth) or temporomandibular disorders, affect the OHRQoL [9-11].

The literature regarding the OHRQoL of patients after SOT is rare, and no systematic evaluation of different groups after SOT is available. However, it has already been documented that clinical oral health conditions are often poor in SOT recipients [12-16]. Thereby, reduced oral health behaviour, i.e., the low use of interdental cleaning devices and a switch from control- to complaintoriented dental behaviour, can be observed [12-16]. These findings indicate that patients after SOT might concede their oral health situation as a low priority. This might be critical because oral diseases can constitute a risk for systemic infectious complications in these patients caused by their lifelong immunosuppressive medication $[1,17,18]$. Therefore, it would be of interest to determine whether the OHRQoL of SOT recipients is generally reduced and influenced by oral and/or diseaserelated parameters to draw conclusions on their appropriate multidisciplinary dental care.

This systematic review aimed to reveal the OHRQoL of patients after SOT, including KTx, LTx, LuTx and HTx. In addition to the OHRQoL of the patients in general, a second focus was to examine differences compared to healthy controls and/or patients before SOT (preTx). Furthermore, associations with HRQoL, oral health and disease-related parameters were considered. Therefore, the main objective was whether patients after SOT would show a reduced OHRQoL compared to healthy individuals.

\section{Methods}

The authors followed the criteria established in the Preferred Reporting Items for Systematic Reviews and MetaAnalyses (PRISMA) guidelines for this review [19].

\section{Focused question}

The PICO (patients, intervention, comparison, outcome) question of the article was whether patients after SOT would show a reduced OHRQoL. Accordingly, patients were individuals after SOT, while an intervention was not defined. The comparison was either a healthy control, patients before SOT or national reference values, and the outcome was an OHRQoL measurement. It was hypothesized that the OHRQoL of SOT patients would be nearly unaffected and not primarily associated with oral health parameters.

\section{Eligibility criteria}

The following inclusion criteria were formulated previously: publication until 31 October 2020, examination of adult patients (age at least 18 years) with SOT, reporting of an OHRQoL measurement outcome and full text in English language.

\section{Search strategy}

Two independent individuals performed this systematic review in November 2020. The literature search was based on the PubMed, Web of Science and Scopus databases, whereby the following search terms were applied: "transplantation" AND "oral health-related quality of life". Additionally, a manual search was performed based on the references of the findings and similar articles. The respective findings were screened for eligibility.

\section{Data extraction}

Within qualitative analysis, the following information was extracted from the included investigations:

- transplanted organ, year of publication, number of participants, study type, age, gender, disease duration.

- recruitment of a healthy control group or patients before SOT for comparison of OHRQoL findings.

- oral examinations and respective findings, if applicable.

- OHRQoL assessment, including form of measurement and results (mean values).

- potential relationship between OHRQoL and general and/or disease-related parameters. 
- findings for subscales of the OHRQoL measurements, if applicable.

If patients were also part of previously published investigations, only the most recent study was included in the analysis. The whole process of systematic search and study selection as well as qualitative analysis was executed by two independent reviewers.

\section{Quality assessment}

For quality appraisal of the seven included studies, the 11-item checklist as recommended by the Agency for Healthcare Research and Quality (AHRQ) for cross-sectional studies was applied [20]. To determine a total score for the assessment, the answers "no" or "unclear" were rated as 0 , and the answer "yes" was rated as 1 point for each question. A total score of $0-3$ indicated low quality, a score of 4-7 indicated moderate quality, and a score of 8-11 indicated high quality of the respective study. The quality assessment was independently conducted by the first author (GS) and the senior author (DZ). Any disagreements were discussed and resolved with the two other authors.

\section{Results}

Search findings

Based on the abovementioned search terms, 54 studies were found and were complemented by two more studies included by the manual search. After removal of duplicates and screening of the records, 26 full-text findings were checked for eligibility. While 19 studies did not meet the inclusion criteria (Additional file 1: Supplementary Table 1), seven clinical studies were included in the qualitative synthesis (Fig. 1).

\section{Quality assessment}

The findings of the quality appraisal are given in Table 1 . The majority of studies, i.e., 6/7, indicated scores of moderate quality, while one study showed high quality [21].

\section{Characteristics of the included studies}

Table 2 summarizes the characteristics of the included examinations. Three studies examined patients after KTx [21, 23, 27], two examined HTx [22, 26] and one study each examined patients after LuTx [24] or LTx [25]. All of the studies were performed in Europe, whereby most investigations took part in Germany. The number of included individuals ranged between 39 and

Table 1 Quality assessment of the included studies following the Agency for Healthcare Research and Quality (ARHQ) methodology checklist [20]

\begin{tabular}{|c|c|c|c|c|c|c|c|}
\hline Item & $\begin{array}{l}\text { Segura-Saint- } \\
\text { Gerons et al. } \\
\text { [22] }\end{array}$ & $\begin{array}{l}\text { Schmalz } \\
\text { et al. } \\
{[23]}\end{array}$ & $\begin{array}{l}\text { Schmalz } \\
\text { et al. } \\
{[24]}\end{array}$ & $\begin{array}{l}\text { Schmalz } \\
\text { et al. } \\
{[25]}\end{array}$ & $\begin{array}{l}\text { Ruokonen } \\
\text { et al. [21] }\end{array}$ & $\begin{array}{l}\text { Schmalz } \\
\text { et al. } \\
{[26]}\end{array}$ & $\begin{array}{l}\text { Oduncuoğlu } \\
\text { et al. [27] }\end{array}$ \\
\hline $\begin{array}{l}\text { 1) Define the source of information (survey, record } \\
\text { review) }\end{array}$ & Yes & Yes & Yes & Yes & Yes & Yes & Yes \\
\hline $\begin{array}{l}\text { 2) List inclusion and exclusion criteria for exposed and } \\
\text { unexposed subjects (cases and controls) or refer to } \\
\text { previous publications }\end{array}$ & Yes & Yes & Yes & Yes & Yes & Yes & Yes \\
\hline 3) Indicate time period used for identifying patients & No & No & Yes & No & Yes & No & Yes \\
\hline $\begin{array}{l}\text { 4) Indicate whether or not subjects were consecutive if } \\
\text { not population-based }\end{array}$ & Yes & Yes & Yes & Yes & Yes & Yes & Yes \\
\hline $\begin{array}{l}\text { 5) Indicate if evaluators of subjective components of } \\
\text { study were masked to other aspects of the status of } \\
\text { the participants }\end{array}$ & No & No & No & No & No & No & No \\
\hline $\begin{array}{l}\text { 6) Describe any assessments undertaken for quality } \\
\text { assurance purposes (e.g., test/retest of primary out- } \\
\text { come measurements) }\end{array}$ & Yes & Yes & Yes & Yes & Yes & Yes & Yes \\
\hline 7) Explain any patient exclusions from analysis & NA & NA & NA & NA & Yes & NA & NA \\
\hline $\begin{array}{l}\text { 8) Describe how confounding was assessed and/or } \\
\text { controlled }\end{array}$ & Yes & $U$ & $U$ & U & $U$ & Yes & Yes \\
\hline $\begin{array}{l}\text { 9) If applicable, explain how missing data were handled } \\
\text { in the analysis }\end{array}$ & NA & NA & NA & NA & NA & NA & NA \\
\hline $\begin{array}{l}\text { 10) Summarize patient response rates and completeness } \\
\text { of data collection }\end{array}$ & Yes & Yes & Yes & Yes & Yes & Yes & Yes \\
\hline $\begin{array}{l}\text { 11) Clarify what follow-up, if any, was expected and the } \\
\text { percentage of patients for which incomplete data or } \\
\text { follow-up was obtained }\end{array}$ & NA & NA & NA & NA & Yes & NA & NA \\
\hline Total score & 6 & 5 & 6 & 5 & 8 & 6 & 7 \\
\hline
\end{tabular}



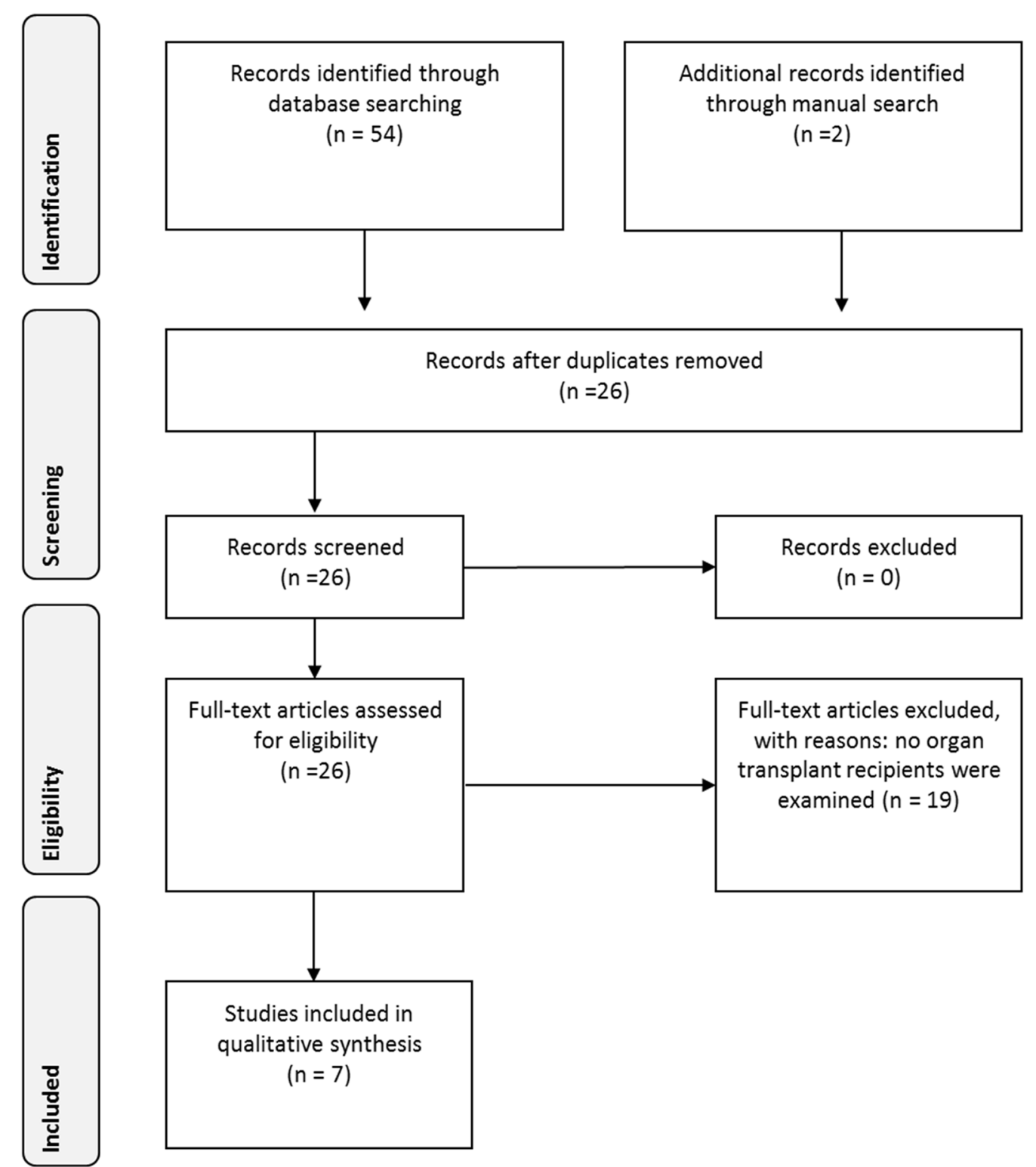

Fig. 1 PRISMA diagram reflecting the study selection during the systematic review [42]

150 participants, with a mean age between 37.90 and 61 years. One study did not include a control group [22], one study included a healthy control group [24], two studies included a control group of patients before SOT $[21,26]$ and three studies included both a healthy control group and individuals before SOT for comparison [23, $25,27]$.

\section{Oral health records and findings}

Oral health examinations were heterogeneous between groups (Table 3). Six studies reported missing or remaining teeth of the patients, whereby the number of missing teeth varied between 3.69 and 9.5 [21, 23-27]. Of note, three studies defined 6 remaining teeth [23-25] and one study defined 10 remaining teeth as inclusion criteria [27]. The prevalence of moderate to severe periodontitis or periodontal treatment need was approximately high. Oral hygiene findings were only reported once [27].

\section{OHRQoL measurements and results}

The majority of studies (5/7) reported the short form of the "Oral Health Impact Profile" (OHIP 14) [23-27]. One study reported the long form (OHIP 49) [22], one study presented a self-composed "oral health quality score" 
Table 2 Overview of the study-specific parameters of the included studies. Values are presented as the mean values \pm standard deviation, mean values (range) or percentages

\begin{tabular}{|c|c|c|c|c|c|c|c|c|c|}
\hline \multirow[t]{2}{*}{ Author, year } & \multirow[t]{2}{*}{ Treatment } & \multirow[t]{2}{*}{ Country } & \multirow{2}{*}{$\begin{array}{l}\text { No. } \\
\text { of patients }\end{array}$} & \multirow[t]{2}{*}{ Study type } & \multirow{2}{*}{$\begin{array}{l}\text { Subjects } \\
\text { mean age } \\
\text { in years }\end{array}$} & \multirow[t]{2}{*}{ Time since Tx } & \multirow{2}{*}{$\begin{array}{l}\text { Female } \\
(\%)\end{array}$} & \multicolumn{2}{|c|}{ Control group for OHRQoL } \\
\hline & & & & & & & & $\mathrm{HC}$ & preTx \\
\hline $\begin{array}{l}\text { Segura-Saint- } \\
\text { Gerons et al. } \\
{[22]}\end{array}$ & $H T x$ & Spain & 150 & $\begin{array}{l}\text { Monocen- } \\
\text { tric cross- } \\
\text { sectional }\end{array}$ & $54.94 \pm 14.56$ & $\begin{array}{l}30.7 \%<5 \text { years, } 32 \% \\
5-10 \text { years, } 37.3 \% \\
>10 \text { years }\end{array}$ & $21.3 \%$ & No & No \\
\hline $\begin{array}{l}\text { Schmalz et al. } \\
\text { [23] }\end{array}$ & $\mathrm{K} T \mathrm{x}$ & Germany & 39 & $\begin{array}{l}\text { Multicentric } \\
\text { cross- } \\
\text { sectional }\end{array}$ & $56.51 \pm 11.56$ & $\mathrm{n} / \mathrm{a}$ & $51.3 \%$ & $\begin{array}{l}\text { Yes, } n=91 \text {, age: } \\
58.31 \pm 9.91 \text { years, } \\
65.9 \% \text { female }\end{array}$ & $\begin{array}{l}\text { Yes, HD n=87, } \\
\text { 37.9\% Female, age: } \\
60.98 \pm 14.01\end{array}$ \\
\hline $\begin{array}{l}\text { Schmalz et al. } \\
\text { [24] }\end{array}$ & LuTx & Germany & 60 & $\begin{array}{l}\text { Monocen- } \\
\text { tric cross- } \\
\text { sectional }\end{array}$ & $54.03 \pm 9.97$ & $>6$ years: $58.3 \%$ & $50 \%$ & $\begin{array}{l}\text { Yes, } n=70 \text {, age: } \\
55.44 \pm 8.54 \text { years, } \\
63 \% \text { female }\end{array}$ & No \\
\hline $\begin{array}{l}\text { Schmalz et al. } \\
\text { [25] }\end{array}$ & LTx & Germany & 47 & $\begin{array}{l}\text { Monocen- } \\
\text { tric cross- } \\
\text { sectional }\end{array}$ & $46.6 \pm 12.6$ & $4.7 \pm 3.9$ years & $42.6 \%$ & $\begin{array}{l}\text { Yes, } n=75,58.7 \% \\
\quad \text { female, } 57.1 \pm 9.9\end{array}$ & $\begin{array}{l}\text { Yes, preLTx } n=24, \\
41.7 \% \text { female, } \\
54.4 \pm 9.5 \text { years }\end{array}$ \\
\hline $\begin{array}{l}\text { Ruokonen } \\
\text { et al. [21] }\end{array}$ & $\mathrm{K} T \mathrm{x}$ & Finland & 51 & $\begin{array}{l}\text { Prospective } \\
\text { observa- } \\
\text { tional }\end{array}$ & $61(31-86)$ & $7.1(1-11)$ years & $33 \%$ & No & $\begin{array}{l}\text { Yes, predialysis } \\
\mathrm{n}=144,32.6 \% \\
\text { female, age } \\
23-83 \text { years }\end{array}$ \\
\hline $\begin{array}{l}\text { Schmalz et al. } \\
\text { [26] }\end{array}$ & $H T x$ & Germany & 104 & $\begin{array}{l}\text { Monocen- } \\
\text { tric cross- } \\
\text { sectional }\end{array}$ & $55.26 \pm 12.16$ & $6.8 \pm 5.16$ years & $25 \%$ & No & $\begin{array}{l}\text { Yes, } \mathrm{HI} n=82 \\
54.90 \pm 11.14 \text { years, } \\
15.9 \% \text { female }\end{array}$ \\
\hline $\begin{array}{l}\text { Oduncuoğlu } \\
\text { et al. [27] }\end{array}$ & KTx & Turkey & 64 & $\begin{array}{l}\text { Monocen- } \\
\text { tric cross- } \\
\text { sectional }\end{array}$ & $37.90 \pm 10.30$ & $\begin{array}{l}1 \text { year } \\
18.8 \%,<1-5 \text { years } \\
45.3 \%,>5 \text { years } \\
35.9 \%\end{array}$ & $31.2 \%$ & $\begin{array}{l}\text { Yes, } n=61 \\
37.10 \pm 13.41 \\
65.6 \% \text { female }\end{array}$ & $\begin{array}{l}\text { Yes, } \mathrm{HD} n=63 \\
40.98 \pm 9.99 \text { years, } \\
38.1 \% \text { female }\end{array}$ \\
\hline
\end{tabular}

OHRQoL oral health-related quality of life, $n / a$ : not applicable, $H D$ haemodialysis, $H$ I heart insufficiency

(OHQS) [21] and one investigation additionally included the OHRQoL-UK questionnaire (Table 4) [27]. The OHIP 14 values ranged between 1.70 and 8.9 points. Only one study found better OHRQoL in patients after SOT compared to a preTx group [27]. Similarly, only one study confirmed worse OHRQoL in SOT recipients than in healthy controls [25]. Two studies each revealed an association and/or correlation between OHRQoL and general health-related quality of life (HRQoL) [21, 26], oral health parameters [21, 22] or disease-related parameters [22, 27]. Three studies reported OHRQoL subscales, whereby different subscales were applied (Table 5) [22, 26, 27].

\section{Discussion}

This systematic review revealed seven clinical studies that examined the OHRQoL of patients after SOT. Only one study each found the OHRQoL of SOT recipients to be different compared to patients before SOT and healthy controls. Accordingly, it is difficult to evaluate whether the OHRQoL of these patients is reduced or impaired by their oral and/or systemic conditions. The majority of studies applied the OHIP 14, a valid and well-established questionnaire-based measurement that evaluates 14 different functional and psychosocial impairments that patients perceived with respect to their oral cavity (Additional file 1: Supplementary Table 2) [7, 28, 29]. Due to cross-cultural differences between different OHIP translations [29] and differences in patient groups and health systems between different countries, the comparability of the included studies might be limited. While no international reference values are available, the German reference can be used to estimate whether there is a reduction in the OHRQoL of patients after SOT. For OHIP 14, a reference value between 0 and 4 out of 56 points, whereby higher values indicate worse OHRQoL, can be stated based on the dentition of patients [30]. Three of the included studies, which were performed in Germany, are within this reference [23-25]. Two other studies using OHIP 14 presented slightly higher scores $[26,27]$. Another study applied the OHIP 49, which is the long version of OHIP 14, of which a score between 5 and 15 out of 196 points can be seen as a reference [31]. Accordingly, the reported OHIP 49 lies slightly higher than the reference [22]. Although a general statement regarding the OHRQoL of SOT recipients is limited due to different patient cohorts (different organs, countries, mean age, oral status), the OHRQoL of these patients appears not or at most slightly reduced.

Several issues need to be discussed in this context. In general, the physical oral health findings in relation to the patients' perception of their oral conditions seem contradictory. In a Turkish study, which applied OHIP 14, the worst OHRQoL was found [27]. This study had the lowest mean age and lowest number of missing teeth out 
Table 3 Examined oral health parameters and the main results of oral conditions if they were presented as the mean values \pm standard deviation, means (range) or percentages in the included studies

\begin{tabular}{|c|c|c|c|c|c|}
\hline Author, year & $\begin{array}{l}\text { Tooth loss, remaining } \\
\text { teeth, dentures }\end{array}$ & $\begin{array}{l}\text { Dental diseases, caries, } \\
\text { dental treatment need }\end{array}$ & Oral hygiene indices & $\begin{array}{l}\text { Periodontal } \\
\text { parameters, } \\
\text { periodontal treatment } \\
\text { need }\end{array}$ & $\begin{array}{l}\text { Further } \\
\text { oral health } \\
\text { parameters }\end{array}$ \\
\hline $\begin{array}{l}\text { Segura-Saint-Gerons et al. } \\
\text { [22] }\end{array}$ & $38 \%$ denture wearing & $\mathrm{n} / \mathrm{a}$ & $\mathrm{n} / \mathrm{a}$ & $\mathrm{n} / \mathrm{a}$ & $\mathrm{n} / \mathrm{a}$ \\
\hline Schmalz et al. [23] & M-T: $7.15 \pm 6.21^{*}$ & $\begin{array}{l}\text { DMF-T: } 17.41 \pm 5.51 \\
\text { D-T } 0.74 \pm 0.43, \text { F-T: } \\
9.51 \pm 4.23\end{array}$ & $\mathrm{n} / \mathrm{a}$ & $\begin{array}{l}87.2 \% \text { Moderate to } \\
\text { severe periodontitis }\end{array}$ & $\mathrm{n} / \mathrm{a}$ \\
\hline Schmalz et al. [24] & M-T: $8.17 \pm 5.82^{*}$ & $\begin{array}{l}\text { DMF-T: } 20.53 \pm 5.09 \\
\text { D-T: } 0.82 \pm 1.85, \text { F-T } \\
11.55 \pm 4.57\end{array}$ & $\mathrm{n} / \mathrm{a}$ & $\begin{array}{l}\text { 98\% Moderate to severe } \\
\text { periodontitis }\end{array}$ & $\mathrm{n} / \mathrm{a}$ \\
\hline Schmalz et al. [25] & M-T: $9.5 \pm 5.6^{*}$ & $\begin{array}{l}\text { DMF-T: } 21.6 \pm 5.2 \\
\text { D-T: } 1.5 \pm 2.2, \mathrm{~F}-\mathrm{T} \\
11.55 \pm 4.57\end{array}$ & $\mathrm{n} / \mathrm{a}$ & $\begin{array}{l}74.5 \% \text { moderate to } \\
\text { severe periodontitis }\end{array}$ & $\mathrm{n} / \mathrm{a}$ \\
\hline Ruokonen et al. [21] & $\begin{array}{l}\text { Remaining teeth: } \\
21.7 \pm 6.8\end{array}$ & $\mathrm{n} / \mathrm{a}$ & $\mathrm{n} / \mathrm{a}$ & $\mathrm{n} / \mathrm{a}$ & $\begin{array}{l}\text { Xerostomia } \\
\text { 40\%, } \\
\text { UWSF } \\
0.32, \\
\text { SWSF: } \\
0.95\end{array}$ \\
\hline Schmalz et al. [26] & M-T: $6.90 \pm 7.27$ & $\begin{array}{l}\text { DMF-T: } 16.08 \pm 7.11 \\
\text { dental treatment need: } \\
16.3 \%\end{array}$ & $\mathrm{n} / \mathrm{a}$ & $\begin{array}{l}\text { Periodontal treatment } \\
\text { need: } 85.6 \%\end{array}$ & $\mathrm{n} / \mathrm{a}$ \\
\hline Oduncuoğlu et al. [27] & M-T: $3.69 \pm 5.39^{* *}$ & $\begin{array}{l}\text { DMF-T: } 5.2 \pm 5.8 \\
\text { D-T: } 1.0 \pm 1.62, \text { F-T: } \\
0.63 \pm 1.52\end{array}$ & $\begin{array}{l}\mathrm{Gl}: 1.33 \pm 0.33, \mathrm{Pl}: \\
\quad 1.68 \pm 0.4\end{array}$ & PPD: $2.48 \pm 0.6$ & $\mathrm{n} / \mathrm{a}$ \\
\hline
\end{tabular}

$M-T$ missing teeth, D-T decayed teeth, F-T filled teeth, DMF-T decayed-, missing- and filled teeth index, PI plaque index, GI gingival index, PPD periodontal probing depth, UWS unstimulated whole saliva, SWS stimulated whole saliva, $n / a$ not applicable

*inclusion criterion: at least 6 remaining teeth

** inclusion criterion: at least 10 remaining teeth

of all included studies (Table 1). However, age and tooth loss regularly affect OHRQoL $[9,32,33]$. Accordingly, the reduced OHRQoL of this cohort of Turkish patients is surprising and might indicate a perception of oral health situation, which is not in line with the clinical situation. Because this study did not examine associations between oral health and OHRQoL of the patients, this factor remains speculative. In contrast, four German studies found the OHRQoL to be independent of insufficient dental and periodontal status [23-26]. These four studies found a high periodontitis prevalence or treatment need (Table 1). In regular cases, this should lead to an impairment of OHRQoL [10, 34]. Accordingly, the findings also argue for a patient's perception of the oral health situation, which is not in line with the clinical situation. However, the included studies did not report in detail the extent or severity of periodontal diseases (e.g., tooth loosening, pronounced recession, active inflammation). Only one study, performed in Finland, revealed associations between physical oral findings and OHRQoL [21]. Therefore, OHRQoL was assessed by a self-composed questionnaire (OHQS), including questions on last dental check-up, toothbrushing, smoking or dry mouth [21].
This questionnaire is not comparable to regular OHRQoL assessment with the OHIP, which assesses different functional and psychosocial impacts of the patient and not oral behaviour (Additional file 1: Table 2). The study by Segura-Saint-Gerons et al. found associations between OHIP 49 and oral behaviour (tooth brushing and dental visits) but not with physical oral health [22]. Accordingly, although this conclusion must be interpreted with caution, the OHRQoL of patients after SOT, which is not or only slightly reduced, appears to be mainly independent of physical oral health conditions.

Two studies found a relationship between general HRQoL and OHRQoL $[21,26]$. In general, HRQoL and OHRQoL are closely related in generally healthy individuals, where OHRQoL can be seen as a subaspect of the whole HRQoL [35]. However, specific diseases might affect this relationship to an unclear extent [36]. Furthermore, HRQoL can also be directly associated with oral health conditions [6]. This effect has not yet been considered in examinations of SOT recipients. It is well described that the general HRQoL of SOT recipients is impaired and that different important emotional and psychosocial issues are of relevance $[2,4,5]$. The general 


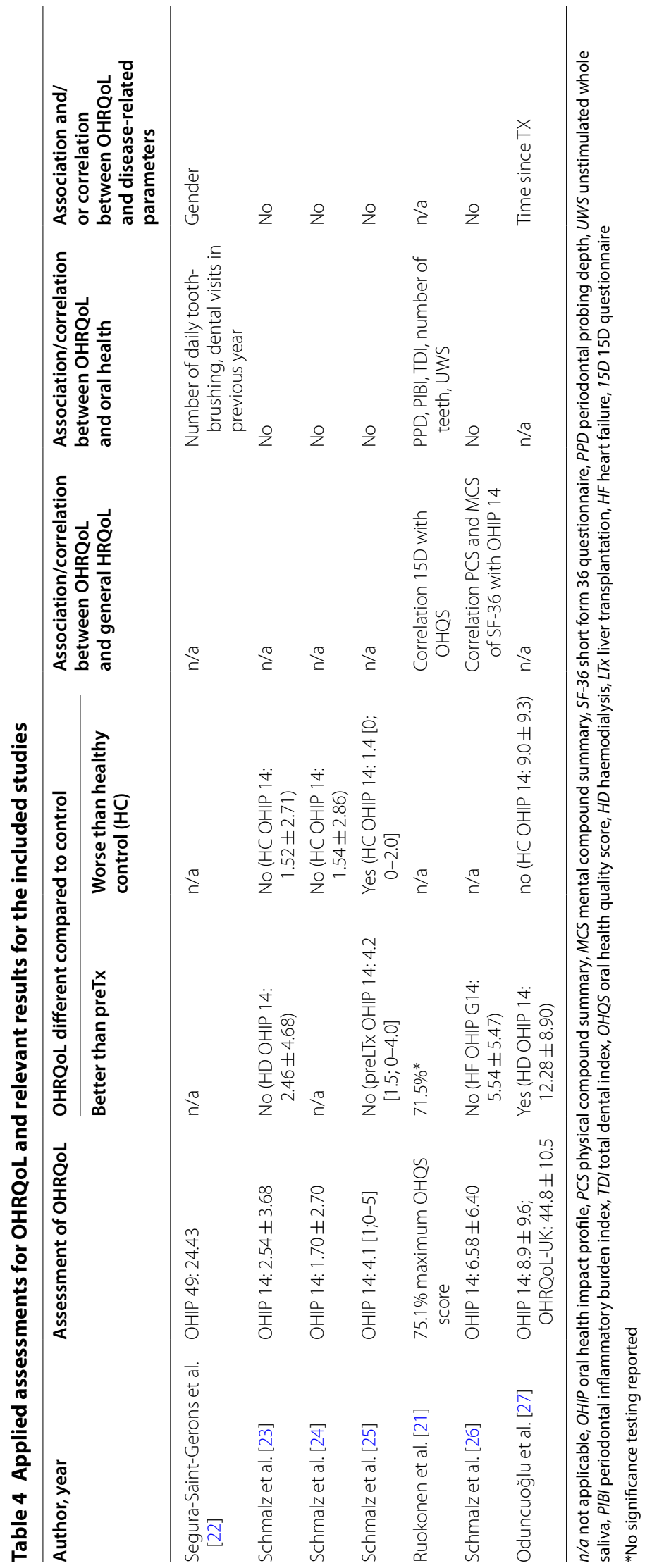




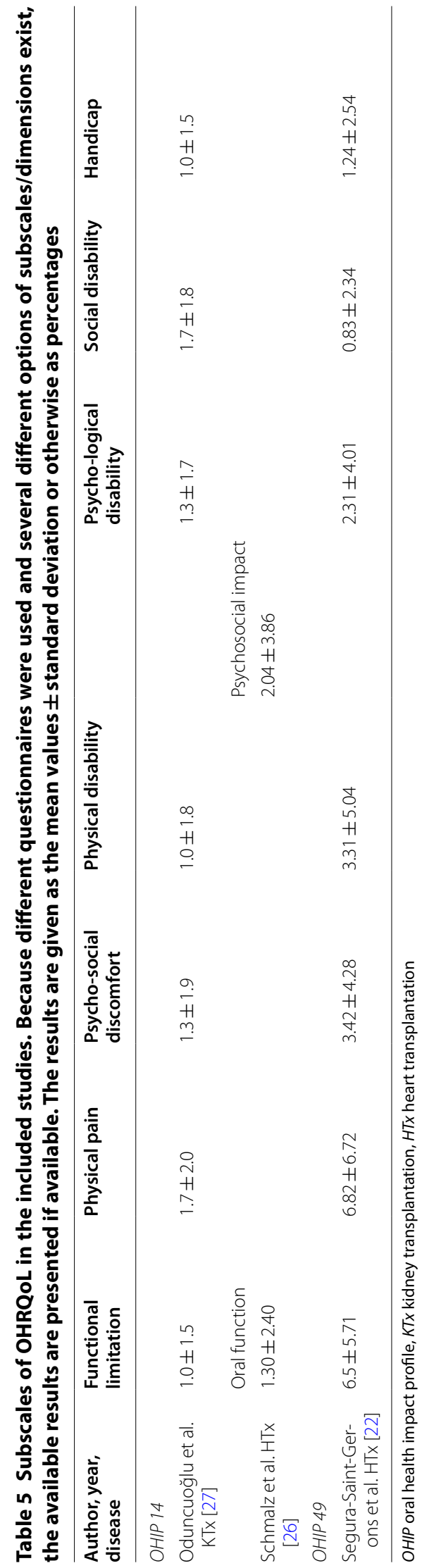


burden related to SOT, medication, psychological issues (acceptance of transplant, perceived relationship to donor) and comorbidities might affect the perception of other areas of life, e.g., oral health and dental behaviour. Based on the missing association between OHRQoL and the physical oral situation on the one hand and the association between OHRQoL and HRQoL on the other hand, a shift in patients' oral health perception can be hypothesized.

In this context, the "response shift theory", as formulated by Sprangers and Schwartz in 1999, can be quoted [37]. This phenomenon describes a cognitive change in patients with severe chronic diseases, which leads to a postponement of the internal standard due to the accommodation of the status "chronic disease" [37]. Of course, the strict transferability of this model in the context of the OHRQoL of SOT recipients is limited; assessment and interpretation of the "response shift" phenomenon is difficult [38, 39]. Previously, "response shift" assessment was applied in the context of dentistry, especially with regard to prosthodontic rehabilitation, assessment of perceived treatment effects or dentine hypersensitivity [40-42]. However, these deliberations were only focused on oral disease or dental therapy measures. Based on the findings of this systematic review, it might be conceivable that the accommodation of the chronically diseased status of SOT recipients might affect their oral health perception. This might lead to a shift in the perception threshold for impairment in OHRQoL and possibly HRQoL caused by oral diseases and conditions. Therefore, patients might not perceive oral diseases, such as chronic periodontitis or several missing teeth, as impairments in their OHRQoL and might be affected only if acute dental issues, such as pain or extended tooth loss, appear (Fig. 2).

Of course, this is just a hypothesis based on the nearly unaffected OHRQoL of SOT recipients independently of their oral status. However, this might be of high practical relevance for dental care. If a patient does not feel impairment of his/her oral condition, this patient might not see the necessity to visit the dentist or to increase oral hygiene behaviour. This would explain the poor clinical oral health conditions and reduced oral health behaviour, i.e., the low use of interdental cleaning devices and a switch from control- to complaint-oriented dental behaviour of SOT recipients [12-16]. However, early dental rehabilitation and sufficient maintenance of SOT recipients are necessary to reduce the risk of systemic infections related to their lifelong immunosuppressive medication [1, 17, 18]. This early and prevention-oriented dental care seems to not work yet [43]. Therefore, multidisciplinary oral care appears necessary. Based on the current findings and formed hypothesis, the interdisciplinary team should include dental staff and transplant centres as well as psychological teams to build awareness of the importance of healthy oral conditions for these patients (Fig. 3).

This is the first systematic review on the OHRQoL of SOT recipients. It was executed according to the PRISMA statement [19] by two independently operating individuals. While based on the search findings, the clinically relevant hypothesis of a phenomenon, which is similar to a "response shift", could be formed, several general methodological issues of the included studies should be recognized. The included studies had certain heterogeneity regarding country, transplanted organs, age, oral examinations and OHRQoL measurements. This is important because a direct comparison between the different organ groups is not possible. However, this is the first systematic insight into the perception of OHRQoL by recipients of different SOT, which revealed common findings of clinical relevance. Because few data are available, the focus on one single organ group currently does not make sense and justifies including the heterogeneous group of different SOT recipients. It is known that oral diseases regularly affect OHRQoL [9-11]. To assess the real influence of oral conditions on the OHRQoL of SOT recipients, profound oral examinations, including the extent and severity of physical oral health impairment, might be necessary. This might include the severity and activity of periodontitis considering the new classification [44] or the number of remaining functional occlusal pairs instead of only assessing the number of missing teeth [9]. Furthermore, standardized and validated instruments, e.g., OHIP 14, should be applied, and future studies should aim to reveal reference values for SOT recipients. Only one study reported on the validity of the OHIP for SOT recipients [27], which should be extended in future research in the field. The reporting and analysis of different subscales, such as oral function, psychosocial impact, pain or orofacial appearance, might increase the understanding of individual patient cases [8]. Moreover, HRQoL and disease-related parameters as well as psychological issues, such as anxiety and/or depression, need to be considered to allow a complex understanding of the OHRQoL of these patients. Furthermore, longitudinal studies are needed to prove the hypothesis of a "response shift", for which valid methods should be used [38, 39]. In general, assessment of the OHRQoL of patients after SOT can help understand the complexity of this patient group and to develop dental special care, which could allow successful, patient-oriented and multidisciplinary therapy and disease prevention. 


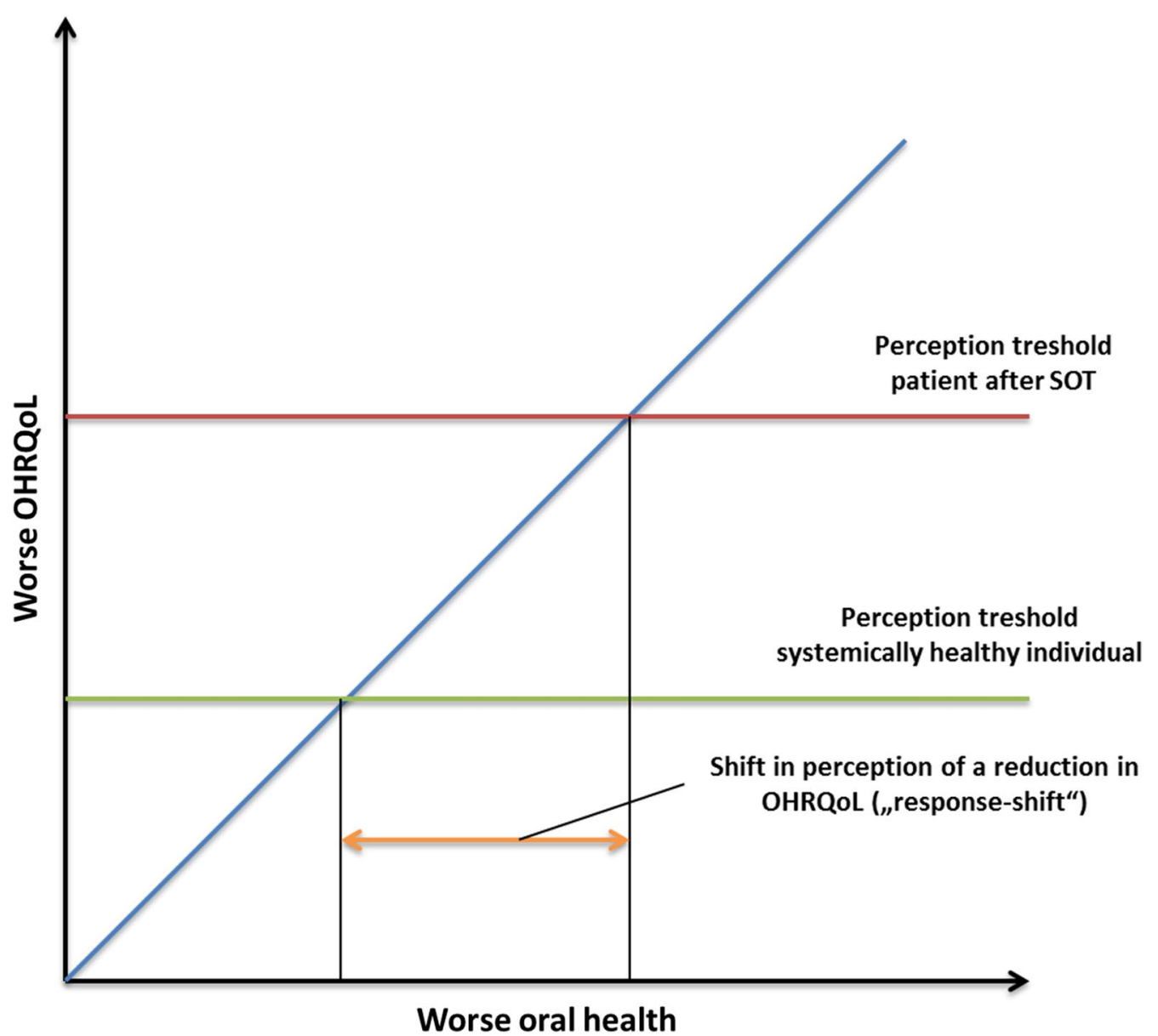

Fig. 2 Change in the perception of the patients' oral health situation due to the burden of SOT and related parameters, such as psychological, physical and social impairment

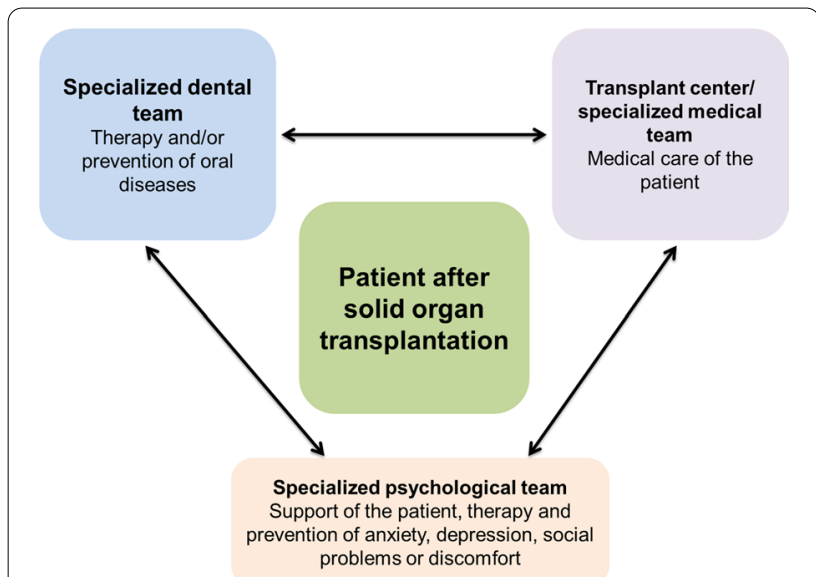

Fig. 3 For sufficient, patient-oriented oral care of SOT recipients, a multidisciplinary team might be necessary to build awareness of the importance of healthy oral conditions

\section{Conclusions}

Patients after SOT show an unaffected or slightly reduced OHRQoL, which is mainly independent of the insufficient oral status. A possible reason could be a shift in the perception threshold for oral diseases and conditions caused by the general health burden related to SOT. This might indicate the necessity for multidisciplinary dental care to (re)build patients' awareness of the importance of oral health. Well-designed, longitudinal studies are needed to prove these conclusions.

\section{Supplementary information}

Supplementary information accompanies this paper at https://doi. org/10.1186/s12903-020-01350-w.

Additional file 1: Supplementary Table 1 and Supplementary Table 2.

Abbreviations

D-T: Number of decayed teeth; DMF-T: Decayed-, missing- and filled teeth index; F-T: Number of filled teeth; GI: Gingival index; HRQoL: Health-related 
quality of life; $\mathrm{HTX}$ : Heart transplantation; $\mathrm{KTX}$ : Kidney transplantation; LTx: Liver transplantation; LuTx: Lung transplantation; M-T: Number of missing teeth; OHIP: Oral health impact profile; OHRQoL: Oral health-related quality of life; PI: Plaque index; PICO: Patient, intervention, control, outcome; PPD: Periodontal probing depth; SOT: Solid organ transplantation; TX: Transplantation.

\section{Acknowledgements}

The authors acknowledge support from Leipzig University for Open Access Publishing.

\section{Authors' contributions}

GS conceptualized the research, conducted a systematic review, analysed and interpreted the results and wrote the manuscript. JG participated in data analysis and interpretation and revised the manuscript. OK participated in data analysis and interpretation and revised the manuscript. DZ conducted the systematic review, participated in data analysis and interpretation and drafted the manuscript. All authors gave their final approval. All authors read and approved the final manuscript.

\section{Funding}

Open Access funding enabled and organized by Projekt DEAL. This study did not receive funding.

\section{Availability of data and materials}

All data generated or analysed during this study are included in this published article.

\section{Ethics approval and consent to participate}

Not applicable.

\section{Consent for publication}

Not applicable.

\section{Competing interests}

The authors declare that they have no competing interests.

\section{Author details}

${ }^{1}$ Department of Cariology, Endodontology and Periodontology, University of Leipzig, Liebigstr. 12, 04103 Leipzig, Germany. ${ }^{2}$ University Department of Cardiac Surgery, Heart Center Leipzig, Leipzig, Germany. ${ }^{3}$ Universitäres Bauchzentrum Basel, Universitätsspital Basel, Basel, Switzerland.

Received: 4 September 2020 Accepted: 26 November 2020 Published online: 09 December 2020

\section{References}

1. Kritikos A, Manuel O. Bloodstream infections after solid-organ transplantation. Virulence. 2016;7:329-40.

2. Tarabeih M, Bokek-Cohen Y, Azuri P. Health-related quality of life of transplant recipients: a comparison between lung, kidney, heart, and liver recipients. Qual Life Res. 2020. doi: https://doi.org/10.1007/s11136-02002434-4. [Epub ahead of print]

3. De Pasquale C, Pistorio ML, Veroux M, Indelicato L, Biffa G, Bennardi N, Zoncheddu P, Martinelli V, Giaquinta A, Veroux P. Psychological and psychopathological aspects of kidney transplantation: a systematic review. Front Psychiatry. 2020;11:106.

4. Dąbrowska-Bender M, Kozaczuk A, Pączek L, Milkiewicz P, Słoniewski R, Staniszewska A. Patient quality of life after liver transplantation in terms of emotional problems and the impact of sociodemographic factors. Transpl Proc. 2018;50:2031-8.

5. Cannavò A, Passamonti SM, Vincenti D, Aurelio MT, Torelli R, Poli F, Piccolo G, Cardillo M. North Italy Transplant program. Quality of Life Before and After Transplantation in Solid Organ Recipients Referred to the North Italy Transplant program (NITp): a cross-sectional study. Transpl Proc. 2019;51:1692-8

6. Haag DG, Peres KG, Balasubramanian M, Brennan DS. Oral conditions and health-related quality of life: a systematic review. J Dent Res. 2017;96:864-74.
7. Sischo L, Broder HL. Oral health-related quality of life: what, why, how, and future implications. J Dent Res. 2011;90:1264-70.

8. John MT, Rener-Sitar K, Baba K, Čelebić A, Larsson P, Szabo G, et al. Patterns of impaired oral health-related quality of life dimensions. J Oral Rehabil. 2016:43:519-27.

9. Tan H, Peres KG, Peres MA. Retention of teeth and oral health-related quality of life. J Dent Res. 2016;95:1350-7.

10. Ferreira MC, Dias-Pereira AC, Branco-de-Almeida LS, Martins CC, Paiva SM. Impact of periodontal disease on quality of life: a systematic review. J Periodontal Res. 2017;52:651-5.

11. Dahlström L, Carlsson GE. Temporomandibular disorders and oral health-related quality of life. A systematic review. Acta Odontol Scand. 2010;68:80-5.

12. Ziebolz D, Hraský V, Goralczyk A, Hornecker E, Obed A, Mausberg RF. Dental care and oral health in solid organ transplant recipients: a single center cross-sectional study and survey of German transplant centers. Transpl Int. 2011;24:1179-88.

13. Schmalz G, Kauffels A, Kollmar O, Slotta JE, Vasko R, Müller GA, Haak R, Ziebolz D. Oral behavior, dental, periodontal and microbiological findings in patients undergoing hemodialysis and after kidney transplantation. BMC Oral Health. 2016;16:72.

14. Marcinkowski A, Ziebolz D, Kleibrink BE, Weinreich G, Kamler M, Teschler $\mathrm{H}$, Sommerwerck U. Deficits in oral health behavior and oral health status in patients after lung transplantation. Clin Respir J. 2018;12:721-30.

15. Kauffels A, Schmalz G, Kollmar O, Slotta JE, Weig M, Groß U, Bader O, Ziebolz D. Oral findings and dental behaviour before and after liver transplantation: a single-centre cross-sectional study. Int Dent J. 2017;67:244-51.

16. Binner C, Wagner J, Schmalz G, Eisner M, Rast J, Kottmann T, Haak R, Oberbach A, Borger MA, Garbade J, Ziebolz D. Insufficient oral behaviour and the high need for periodontal treatment in patients with heart insufficiency and after heart transplantation: a need for special care programs? J Clin Med. 2019;8(10).

17. Cajanding R. Immunosuppression following organ transplantation. Part 2: complications and their management. Br J Nurs. 2018;27:1059-65.

18. Guggenheimer J, Mayher D, Eghtesad B. A survey of dental care protocols among US organ transplant centers. Clin Transpl. 2005;19:15-8.

19. Moher D, Liberati A, Tetzlaff J, Altman DG, The PRISMA Group. Preferred reporting items for systematic reviews and meta-analyses: The PRISMA Statement. PLoS Med. 2009;6:e1000097.

20. Rostom A, Dube C, Cranney A, et al. Celiac disease. Evidence reports/ technology assessments, No. 104. Agency for Healthcare Research and Quality (US); 2004. Available from: https://www.ncbi.nlm.nih.gov/books/ NBK35156/

21. Ruokonen $H$, Nylund $K$, Meurman JH, Heikkinen AM, Furuholm J, Sorsa T, Roine R, Ortiz F. Oral symptoms and oral health-related quality of life in patients with chronic kidney disease from predialysis to posttransplantation. Clin Oral Investig. 2019;23:2207-13.

22. Segura-Saint-Gerons R, Segura-Saint-Gerons C, Alcántara-Luque R, et al. Perceived influence of oral health upon quality of life in heart transplant patients. Medicina Oral Patologia Oral Cirurgica Bucal. 2012;17:e409-14.

23. Schmalz G, Kollmar O, Vasko R, Müller GA, Haak R, Ziebolz D. Oral healthrelated quality of life in patients on chronic haemodialysis and after kidney transplantation. Oral Dis. 2016;22:665-72.

24. Schmalz G, Wendorff H, Marcinkowski A, Weinreich G, Teschler H, Haak R, Sommerwerck U, Ziebolz D. Oral health related quality of life depending on oral health and specific factors in patients after lung transplantation. Clin Respir J. 2018;12:731-7.

25. Schmalz G, Meisel A, Kollmar O, Kauffels A, Slotta JE, Kottmann T, Haak R, Ziebolz D. Oral health-related quality of life depending on dental and periodontal health in different patients before and after liver transplantation. Clin Oral Investig. 2018;22:2039-45.

26. Schmalz G, Eisner M, Binner C, Wagner J, Rast J, Kottmann T, Haak R, Oberbach A, Borger MA, Garbade J, Ziebolz D. Oral health-related quality of life of patients after heart transplantation and those with heart failure is associated with general health-related quality of life: a cross-sectional study. Qual Life Res. 2020 doi:https://doi.org/10.1007/s11136-020-02439 -z. [Epub ahead of print]

27. Oduncuoğlu BF, Alaaddinoğlu EE, Çolak T, Akdur A, Haberal M. Effects of renal transplantation and hemodialysis on patient's general health perception and oral health-related quality of life: a single-center 
cross-sectional study. Transpl Proc. 2020 pii: S0041-1345(19)31138-8. doi:https://doi.org/10.1016/j.transproceed.2020.01.016. [Epub ahead of print]

28. Slade GD, Spencer AJ. Development and evaluation of the oral health impact profile. Community Dent Health. 1994;11:3-11.

29. MacEntee MI, Brondani M. Cross-cultural equivalence in translations of the oral health impact profile. Community Dent Oral Epidemiol. 2016;44:109-18

30. John MT, Micheelis W, Biffar R. Reference values in oral health-related quality of life for the abbreviated version of the Oral Health Impact Profile. Swiss Dent J. 2004;114:784-91.

31. John MT, LeResche L, Koepsell TD, Hujoel P, Miglioretti DL, Micheelis W. Oral health-related quality of life in Germany. Eur J Oral Sci. 2003;111:483-91.

32. Colussi PR, Hugo FN, Muniz FW, Rösing CK. Oral health-related quality of life and associated factors in brazilian adolescents. Braz Dent J. 2017;28:113-20.

33. Gerritsen AE, Allen PF, Witter, DJ. Bronkhorst EM, Creugers NHJ. Tooth loss and oral health-related quality of life: a systematic review and metaanalysis. Health Qual Life Outcomes. 2010:8:126.

34. Buset SL, Walter C, Friedmann A, Weiger R, Borgnakke WS, Zitzmann NU. Are periodontal diseases really silent? A systematic review of their effect on quality of life. J Clin Periodontol. 2016;43:333-44.

35. Reissmann DR, John MT, Schierz O, Kriston L, Hinz A. Association between perceived oral and general health. J Dent. 2013;41:581-9.

36. Barrios R, Tsakos G, Gil-Montoya JA, Montero J, Bravo M. Association between general and oral health-related quality of life in patients treated for oral cancer. Med Oral Patol Oral Cir Bucal. 2015;20:e678-84.

37. Sprangers MA, Schwartz CE. Integrating response shift into healthrelated quality of life research: a theoretical model. Soc Sci Med. 1999:48:1507-15.
38. Rapkin BD, Schwartz CE. Advancing quality-of-life research by deepening our understanding of response shift: a unifying theory of appraisal. Qual Life Res. 2019;28:2623-30.

39. Sajobi TT, Brahmbatt R, Lix LM, Zumbo BD, Sawatzky R. Scoping review of response shift methods: current reporting practices and recommendations. Qual Life Res. 2018;27:1133-46.

40. Reissmann DR, Remmler A, John MT, Schierz O, Hirsch C. Impact of response shift on the assessment of treatment effects using the Oral Health Impact Profile. Eur J Oral Sci. 2012;120:520-5.

41. Machuca C, Vettore MV, Krasuska M, Baker SR, Robinson PG. Using classification and regression tree modelling to investigate response shift patterns in dentine hypersensitivity. BMC Med Res Methodol. 2017;17:120.

42. Kimura A, Arakawa H, Noda K, Yamazaki S, Hara ES, Mino T, Matsuka Y, Mulligan R, Kuboki T. Response shift in oral health-related quality of life measurement in patients with partial edentulism. J Oral Rehabil. 2012;39:44-54.

43. Schmalz G, Wendorff H, Berisha L, Meisel A, Widmer F, Marcinkowski A, Teschler H, Sommerwerck U, Haak R, Kollmar O, Ziebolz D. Association between the time after transplantation and different immunosuppressive medications with dental and periodontal treatment need in patients after solid organ transplantation. Transpl Infect Dis. 2018;20:e12832.

44. Caton J, Armitage G, Berglundh T, Chapple ILC, Jepsen S, Kornman KS, Mealey BL, Papapanou PN, Sanz M, Tonetti MS. A new classification scheme for periodontal and peri-implant diseases and conditions-Introduction and key changes from the 1999 classification. J Clin Periodontol. 2018:45:S1-8.

\section{Publisher's Note}

Springer Nature remains neutral with regard to jurisdictional claims in published maps and institutional affiliations.
Ready to submit your research? Choose BMC and benefit from:

- fast, convenient online submission

- thorough peer review by experienced researchers in your field

- rapid publication on acceptance

- support for research data, including large and complex data types

- gold Open Access which fosters wider collaboration and increased citations

- maximum visibility for your research: over $100 \mathrm{M}$ website views per year

At BMC, research is always in progress.

Learn more biomedcentral.com/submissions 